\title{
Building Resilience of Critical Infrastructure: A Case of Impacts of Cyclones on the Power Sector in Odisha
}

\author{
Sujit Kumar Mohanty ${ }^{1, *}$, Ranit Chatterjee ${ }^{2}$ and Rajib Shaw ${ }^{1}$ (D) \\ 1 Graduate School of Media and Governance, Keio University, Tokyo 252-0882, Japan; shaw@sfc.keio.ac.jp \\ 2 Graduate School of Informatics, Kyoto University, Kyoto 606-8501, Japan; ranit13@gmail.com \\ * Correspondence: sujit29@gmail.com
}

Received: 24 April 2020; Accepted: 1 June 2020; Published: 5 June 2020

\begin{abstract}
Odisha is multi-hazard-prone state in the eastern part of India. Among the various disasters, the frequency and severity of cyclones have increased at an alarming rate in the last two decades, which is attributed to climatic change. The state government of Odisha has made great strides in reducing the lives lost in the state, but an increase in economic losses and damage to critical infrastructure has become a point of worry. Considering the power sector as the most crucial of all critical infrastructures, this paper explores the impact that cyclones have had on the sector in the last two decades in Odisha. The $4 \mathrm{R}$ concept of robustness, redundancy, rapidity and resourcefulness is applied to the power sector, and how this is supported by governance is studied. The study points towards need for the master planning of critical infrastructure, based on the risk assessment, establishment of funding mechanisms for mitigation measures and the standardization and quality checking of power sector equipment to withstand the wind speeds of category 4 and above. There needs to be a good coordination between the power sector and the disaster management sector with proper legislative provision. Knowledge management, training and capacity building is another important issue which needs to be focused on.
\end{abstract}

Keywords: critical infrastructure; power sector; cyclone; Odisha; climate and disaster resilience

\section{Introduction}

The frequency and severity of natural hazards are increasing in Asia. As the region is home to many developing countries, the safeguarding of physical and economic development is of immense importance for sustainable development. The critical infrastructure becomes the backbone for not only saving human lives, but also for reducing physical and economic losses. In context of this paper, critical infrastructures can be defined either individually or as a combination of physical structures, facilities, networks and other assets which provide services that are essential to the social and economic functioning of a community or society [1]. The management of these critical infrastructures, owing to their significance for public goods, is interwoven into the governance system of a country. This is reflected in Target D of the Sendai Framework of Action for Disaster Risk Reduction (SFDRR), which calls for a reduction in disaster induced damage to critical infrastructure and the disruption of basic services by developing their resilience by 2030. Further it stresses the need to take national and local action to ensure that they remain safe, effective and operational in pre- and post-disaster scenarios [2].

Asia and the Pacific have achieved dramatic progress in poverty reduction and economic growth over the past 50 years. Investment in infrastructure has had a key role in advancing social and economic development. According to a recent study [3], Asia and the Pacific will need to invest an additional USD 22.6 trillion in infrastructure, or USD 1.5 trillion per year, from 2016 to 2030. This amount does not include the additional investment in resilience needed to address future climate change. Over the same period, the region has experienced a significant increase in the impact of extreme weather 
events, such as tropical cyclones, flooding, droughts, and heat waves [4]. It has also endured major geophysical shocks, including earthquakes and tsunamis. Ongoing climate change could alter the frequency, intensity, extent, duration and timing of extreme weather events, and is likely to result in unprecedented extremes [5].

Infrastructure can be defined in many forms. Community infrastructure consists of both physical infrastructure (also known as community assets) and organisational infrastructure or "hard" and "soft" assets of societies. Infrastructural Resilience (IR), in general terms, refers to "the ability of a system exposed to hazards to resist, absorb, accommodate, adapt to, transform and recover from the effects of a hazard in a timely and efficient manner, including through the preservation and restoration of its essential basic structures and functions through risk management". The effectiveness of a resilient infrastructure rests on its ability to anticipate, absorb, adapt to, and/or rapidly recover from a potentially disruptive event. [6] has identified two board categories of infrastructure, namely, object-orientated systems (OS), such as hospitals, police and fire-stations, etc., and network orientated systems (NS), such as electricity, gas and water which are necessary for daily life. The object-oriented systems mostly include emergency public services and dependent on the network orientated systems for disruption-free service. Hence, the resiliency of the network orientated systems needs to be prioritized over the object-oriented systems. Among the various types of NS servicers, past experiences of disasters suggest that the power sector is the most crucial of all for the functioning of various other services and, at the same time, the most commonly affected service by earthquakes, cyclones or any other disasters.

As India is a rapidly urbanizing developing country, building the resilience of the critical infrastructure is undoubtedly important to sustain this growth. Past disasters in India show a trend of disruption of critical infrastructures and services-mainly the power sector-thus resulting in huge economic loss [7]. The report points out 24 cases of power sector failure since 1974 in India due to floods. In 2012, the world's largest blackout in the power sector hit India, affecting 600 million people across 22 States, thus exposing the vulnerability of the power sector to drought [8] This makes it evident that it is necessary to embed resilient infrastructure concepts into the power sector. In a multi-hazard-prone state, such as Odisha, the damage to the power sector has been enormous in the last two decades, mainly due cyclones.

Given the large number of people living in low-lying and coastal regions, and the large inter-annual variation associated with hydro-meteorological hazards, there is an imminent need to build good quality disaster-control infrastructure. Disaster Control Infrastructure (DCI) are infrastructure assets which are designed specifically to protect populations and assets in hazard-prone locations from the effects of the hazard. DCI includes structures such as river embankments, sea walls, dikes, storm surge barriers, cyclone shelters, etc. The design of these infrastructure systems is based on an understanding of past hazard patterns and expected return periods of extreme hazard events. Uncertainties associated with the local level manifestations of climate change pose a significant challenge in the design of disaster control infrastructure [9].

This paper considers the cases of cyclones in the past two decades that have impacted the state of Odisha in India, especially affecting the power sector. Power infrastructure is considered as a critical infrastructure. As noted in the literature, the power sector has been affected significantly by different past disasters. Therefore, the basic question addressed is how to strengthen the power sector in Odisha with the hypothesis that there will be significant damages if no countermeasures are undertaken. The study uses a case study approach, with data and literature available in the form of legislations, acts and policies, natural calamity memorandums of the government of Odisha, annual reports of the disaster management department and departmental reports and studies. The study does not provide quantitative cost benefit analysis, but rather applies the $4 \mathrm{R}$ concept of physical resilience to identify the gaps in the present system through qualitative policy analysis. The following two sections discuss the importance of critical infrastructure and the need to build their resiliency, especially in the power sector and the various available concepts and methods. The fourth section presents an overview of Odisha's power sector and disaster management setup and elaborates on various cyclone cases and 
their impact on the power sector. The last two sections discuss the findings of the study to suggest possible directions for strengthening the resiliency of the power sector. Since there is no academic analysis of power sector damages in Odisha, this will be first analysis based on the previous data.

\section{Literature Review}

The term critical infrastructure (CI) has varied connotations based on the context of its use. The simplest way of identifying critical infrastructure is by deciding what is fundamental to the normal operations of the society [10]. In similar lines, the [11] defines Critical infrastructure as systems, assets, facilities, and networks that provide essential services for the functioning of the economy and the safety and well-being of the population. These fundamental functions can be individual or a combination of technical assets along with functional sectors and lifeline services. In similar lines, the [12] defines CI as any asset, system or part thereof which is critical to the maintenance of vital societal functions, health, safety, security, economic or social wellbeing of people, the disruption or destruction of which would have a very substantial impact as a result of the failure to maintain those functions. [13] stress high reliability and undisruptive services as the unique qualities which need to be protected for sustainable growth.

The most common definition of resilience is the capacity to bounce back or rebound [14,15] have called resilience a confluence of physical and social systems. UN (2007) defines resilience as the ability of a system, community or society exposed to hazards to resist, absorb, accommodate to and recover from the effects of a hazard in a timely and efficient manner, including through the preservation and restoration of its essential basic structures and functions. [16] have defined resilience in terms of the exposure and adaptability of the outcome. From the available literature, resilience has been studied broadly under these five themes, namely, organizational behaviour and societal planning, ecology, health, economy and engineering [14,17-21]. In this respect, the resilience of Critical Infrastructure is a relatively new field of study [22]. Two of the five themes (societal planning and engineering) are closer to the concept of Critical Infrastructure resilience. From an engineering perspective, the $4 \mathrm{R}$ concept (robustness, resourcefulness, rapidity and redundancy) of resilience can be useful in understanding the resilience of critical infrastructure [17]. Where robustness is the ability to maintain critical operations and functions in the face of crisis, resourcefulness is the ability to skillfully prepare for, respond to and manage a crisis or disruption as it unfolds. Rapidity is the ability to return to and/or reconstitute normal operations as quickly and efficiently as possible after a disruption. Redundancy is availability of alternate resources to support the originals in case of failure. In a planning context, the aim is to create a hazard-resilient community [23].

Resilience, in the context of critical infrastructure, is defined as the ability of a facility or asset to anticipate, resist, absorb, respond to, adapt to, and recover from a disturbance [24,25] suggest a complete assessment of critical infrastructure systems/assets covering all aspects from threat to outcome in a disaster for measuring the resilience of $\mathrm{CI}$ [20]. defines a sustainable city as a network of physical systems and human communities, capable of managing extreme events. During disaster, both must be able to survive and function under extreme stress, and touch upon the interconnectedness of the critical infrastructure with other factors. Furthermore, in the urban context, a city can be called resilient when its physical infrastructure and community is robust and flexible, instead of brittle and fragile. Taking a step back to ponder over the large investments being made in the building and maintaining of critical infrastructure, it is evident that the resilience of $\mathrm{CI}$ is also a function of economic resilience share that the functioning of a given infrastructure is difficult to separate from another, thus leading to the idea of an interdependent system [26].

The transition from CI protection to CI resilience is brought by changes in risk landscape and an increase in uncertainties. A multisectoral system approach is important for building the resiliency of CI to engage stakeholders in design, investment, construction, ownership, operations or regulation. In many of these envisioned roles, the government comes out as an important player. Specifically, a government plays four different roles in CI resilience (1) preparedness for any eventuality (2); policy 
making and regulatory function (3); as an owner or operator of infrastructure (4); as a user or client (OECD, 2011). There are major governmental initiatives regarding critical infrastructure protection (CIP). [27] observe that limited studies have focused on the interconnectedness of the institutional restructuring of critical infrastructures (CIs), privatization, deregulation and liberalization.

Among critical infrastructure, electric power is the most crucial for the global economies [29]. represent the interconnectedness of the various critical infrastructures, shown in Figure 1, thus pointing at a systems approach for better understanding of the gaps that might come up due to various integral issues within this system itself. Figure 1 points out the criticality of the electric power sector in comparison to the other sectors. It is evident that the functioning of electrical power is the service most linked to other services, and its failure is detrimental to the functioning of the other services [30,31].

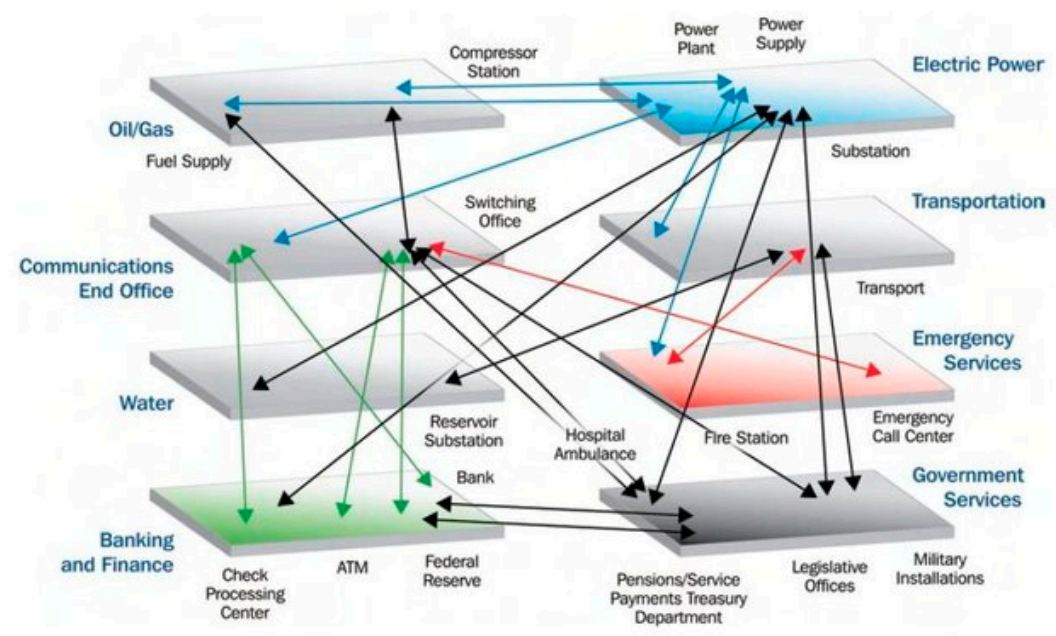

Figure 1. The interlinkages of the critical infrastructure [28].

Another aspect of $\mathrm{CI}$ is a balance between hard and soft infrastructures [32] have argued for the importance of soft assets in smart urban development. Since there has been a tremendous focus on hard infrastructure-focused development, this could omit a primary objective of smart city development, which seeks to put citizens first, not last. First, this is because hard infrastructure comprises "tangible (physical) assets" where investment returns are easily measurable. However, hard assets alone cannot deliver optimal "people-centered" services without human/institutional and other non-physical assets. Second, new gimmicky technologies are an easy investment choice for local government units or other SC project developers. However, hard infrastructure is not always appropriate for many city contexts due to different development objectives, strategies, and resource constraints, including capacity gaps for planning, managing, operating and improving city performance.

Asian Development Bank (ADB) argued that to deliver Strategy 2030 [33], building disaster and climate resilience must be prioritized, while at the same time bringing about prosperous, inclusive and sustainable development, thus, a shift in focus is required. In response, ADB has advanced a holistic resilience approach. The aim is to build climate change and disaster resilience from four key perspectives: physical infrastructure resilience, financial resilience, eco-based resilience and social and institutional resilience. Resilience will be delivered at all levels, to individuals, households, communities, businesses and nations. This holistic approach, in the broader context of sustainable development, encompasses a number of priorities as follows: First, climate change and disaster risks should be taken into account when planning, designing, and building infrastructure projects (physical resilience). Second, there should be greater emphasis on biodiversity and ecosystem services as part of an overall strategy of helping people adapt to climate change and manage disaster risks (eco-based resilience). Third, there should be a focus on the human and social dimensions of climate and disaster resilience (social and institutional resilience). Finally, the financial management of residual disaster risk by countries, businesses, and communities (financial resilience) should be strong and effective, 
and should, in turn, support timely relief, early recovery and reconstruction efforts, and incorporate measures to build back better.

A task report [33] for the European Union pointed out to six major determining factors for the protection of CI. Each of them is listed below:

1. Private and public: how the private and public sector linkage is developed, and how they work in coordination with each other.

2. Unbounded: the role of stakeholders and the identification of malicious activities within the system.

3. Networked: the highly connected stakeholders and the demand to supply balance.

4. Complex: the simplification of complex networks to understand and cater to the problems.

5. Human: the skill and decision-making of the human resource.

6. Vulnerable: The weakness in the system which might expose the CI to damage. This would vary on the type of infrastructure.

7. In addition to the above, in their report, point out four gaps in the CI risk assessment: (1) absence of dependency modelling and analysis; (2) weak consequence analysis; (3) lack of vulnerability assessment; (4) lack of scenario building [34].

8. A study on the resilience of the power sector in developing countries by World Bank points out three gaps: (1) disaster risk management integration in the power sector is weak; (2) awareness of exposure and risk is low; (3) weak organizational capacity; (4) high dependency of external post disaster funding [35].

From the literature review, it is observed that critical infrastructure resilience is important in terms of both hard measures, such as upgrading to proper standards, and also for the soft measures, which include policy, regulations, governance, knowledge management, training, capacity building, etc. Most of the literature globally focuses on the hard infrastructures, while there is a lack of policy/countermeasure analysis. At the national level in India, while there has been some work on national legislation on critical infrastructures-power supply being a state subject in India - no detailed analysis exists at the state level. This paper, therefore, attempts to analyse the past cyclone disasters in Odhisa and draws some lessons for improvements of its power infrastructures.

\section{Methodology}

A case study approach is taken to establish the relation between the power sector (electricity) and the disaster management's governance mechanism in Odisha. How these two institutions interplay can lead to better resilience. Past cases of disasters in specific case study areas were considered for the study. The damage and loss, disruption in services, recovery process, allocation of funding and the subsequent damage and loss in the subsequent disasters was studied from annual reports on natural calamities by the Government of Odisha. In addition, disaster management policies, reports and externally funded projects by various non-governmental actors (UN agencies, World Bank and others) were studied to understand the mitigation measures particular to the power sector being undertaken by the government. A mixed method approach was taken for the study, where the quantitative data set was gathered from the report and descriptive analysis was performed. These were mainly the damage statistics and cost issues from past disasters. The qualitative data analysis most linked to the policies and other legislative measures of the government between 2004 to 2019 was considered. Qualitative data analysis included policies on (national and local) disaster management as well as power sectors. Specific disaster cases were taken as benchmarks to study the damage and loss and governance mechanism.

\subsection{Selection of Odisha as a Case Study}

Odisha is a state in the eastern part of India frequented by floods, cyclones droughts and tsunamis, among other hazards [36]. The state faced the 1999 super cyclone which killed 10,000 people, affecting 
15 million people and causing damaged worth USD 2.5 billion [37]. The state was one of the first to establish a disaster management unit within the government machinery, following the 1999 super cyclone disaster. Needless to say, the power sector was one of the most affected. Following the 1999 super cyclone, Odisha has faced three major cyclonic events-Phailin in 2013, HudHud in 2014 and Fani in 2019-and has been affected by recurring issues of flooding in the last two decades, thus making it an interesting case to study the long term progress in building disaster resilience in its critical infrastructure.

\subsection{Selection of Power Sector as Resilient Infrastructure Case Study}

The energy sector comprises subsystems ranging from power generation to transmission and distribution. It is estimated that, globally, USD 26 trillion will have to be invested in this sector from 2016 to 2030 to sustain the current growth rate. An additional investment of USD 2.9 trillion will be required to meet the SDG targets for the energy sector (IWRI 2018). The various subsystems of energy infrastructure are exposed to disaster risks which can be managed by adopting appropriate standards. While risk assessment and evaluation are hard-wired in the design of assets built since the 1980s, many assets (e.g., hydroelectric dams) currently under operation were commissioned or built prior to this [38]. Additionally, following past disasters, it was observed that the power sector became the most crucial vital infrastructure, and was required to be restored immediately after the disasters, since all other services, such as search and rescue, water supply, telecommunication and health care, depended on the restoration of the power sectors.

\section{Case Study of Odisha}

Some of the states in India, such as Odisha, regularly take the brunt of disasters. Odisha has long been prone to natural and man-made calamities. Floods, droughts and cyclones are regular features in the state. It has been seen that the numbers, severities, frequencies, complexities, and vulnerabilities of the hazards have increased quite rapidly. In the past 50 years, the state has witnessed more than 17 floods and over seven cyclones. The cyclones, ranging from the 1999 super cyclone to cyclones Phailin in 2013, HudHud in 2014, Titli in 2018, Fani and Bulbul in 2019, have resulted in severe devastation in Odisha. This section details the structure of the power sector and disaster management in Odisha. Furthermore, this section deals in overall damage and loss due to various disasters in Odisha, and specifically the damage and loss incurred by the electricity sector.

\subsection{The Power Sector in Odisha}

Odisha is the first state in India to have reformed the power sector for increased efficacy. The state electricity board was decentralized and the Grid Corporation of Odisha Limited (GRIDCO) was made responsible for the transmission and distribution of electricity. In 1995 Odisha brought structural reforms by enacting the Odisha Electricity Reforms Act. A pointed out that the reforms were mostly unsuccessful in changing the tide of loss in revenue due to a lack of baseline data and poor data quality to carry out the reforms [37]. Two more acts subsequently came up: The Electricity Regulatory Commission Act, 1998 and the Electricity Act, 2003, which focused on regulatory boards and tariffs, respectively. Further, to narrow down the financial losses, in 2001, a bailout package was introduced to cushion losses, in 2012 a financial restructuring package was introduced to reduce cumulative debt burden and in 2015, the UDAY (Ujwal DISCOM Assurance Yojana) scheme was introduced to improve performance and reduce losses [38]. Power distribution system of Odisha is presented in Figure 2. 


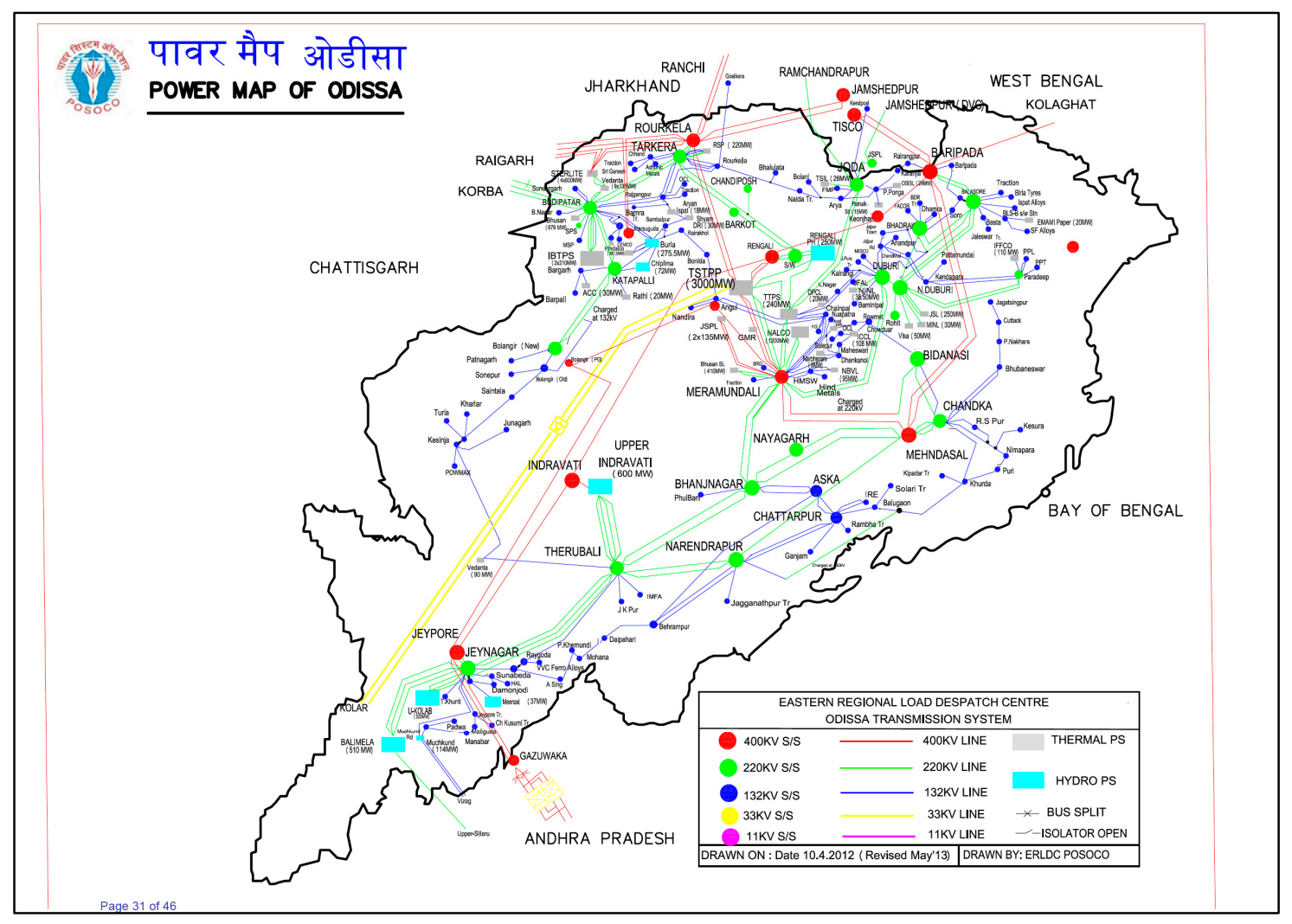

Figure 2. Power distribution system of Odisha.

\subsection{Disaster Management in Odisha}

The Special Relief Organization was created under the Board of Revenue in 1965-1966 for relief and rescue operations during and after the occurrences of various natural calamities. The super cyclone of 1999 made the state government change its relief-centric approach to a preparedness and mitigation-centric approach, and a need for a specialized agency for integrated planning, mobilization of resources, effective disaster mitigation and management was felt, which steered the formation of the Odisha State Disaster Mitigation Authority (OSDMA) in 1999. OSDMA was established as an autonomous state agency registered under the Societies Registration Act, 1860 as a non-profit charitable institution with jurisdiction over the entire state of Odisha. The Revenue and Disaster Management Department has been the administrative department of OSDMA since 2000. Later, in 2008, it was renamed the Odisha State Disaster Management Authority (OSDMA). Odisha state has currently established a State Disaster Response Fund.

The National Disaster Management Act of 2005 led to an institutional rearrangement of disaster management in Odisha, with the establishment of new bodies, forces, and funds. Accordingly, Odisha constituted the State Disaster Management Authority (SDMA) at the state level and the District Disaster Management Authority (DDMA) at the district level. The State Executive Committee (SEC) has been constituted under the Chairmanship of the Chief Secretary to coordinate all disaster management activities of the state. The office of the Special Relief Commissioner and the Odisha State Disaster Management Authority (OSDMA), under the Revenue and Disaster Management Department, assist the SEC in effective disaster management in the state [39]. In case of any disaster, the SRC coordinates with districts and other departments for prompt relief and rescue operations, reconstruction and rehabilitation work. 


\subsection{State and Departmental Disaster Management Plans in Odisha}

Odisha Disaster Management Plan acknowledges three factors-use of substandard electrical fittings, lack of check-up of overused electrical items and limited number of trained electricians-leading to electrical accidents $[40,41]$. These three reasons are also of importance for improving the resilience of the power infrastructure in Odisha. The plan further stresses the need to restore and repair electrical lines and other infrastructure as of the utmost priority, and earmarks normative cost (up to INR 4000 per pole and Rs.0.50 lakh INR per km; 1 Lakh is 100,000, and USD 1 = INR 75 as of current cost). This is important for coming up with pre-disaster agreements with private sector organizations.

The energy department of Odisha drew up its disaster management plan in 2015. The plan identified that transmission lines, owing to their height, are highly vulnerable to cyclones. These lines are vulnerable to falling trees in forest areas. The current design of equipment does not optimize the factor of safety. Furthermore, the span length of the wire and base design of the towers are varying across the state. In addition, the low laying substations are prone to flooding, following a cyclone. Moreover, the quick supply of towers and poles and accessibility to remote locations remain a challenge for the energy department. Risk assessments for cyclones have been done for five districts, as shown in Figure 3.

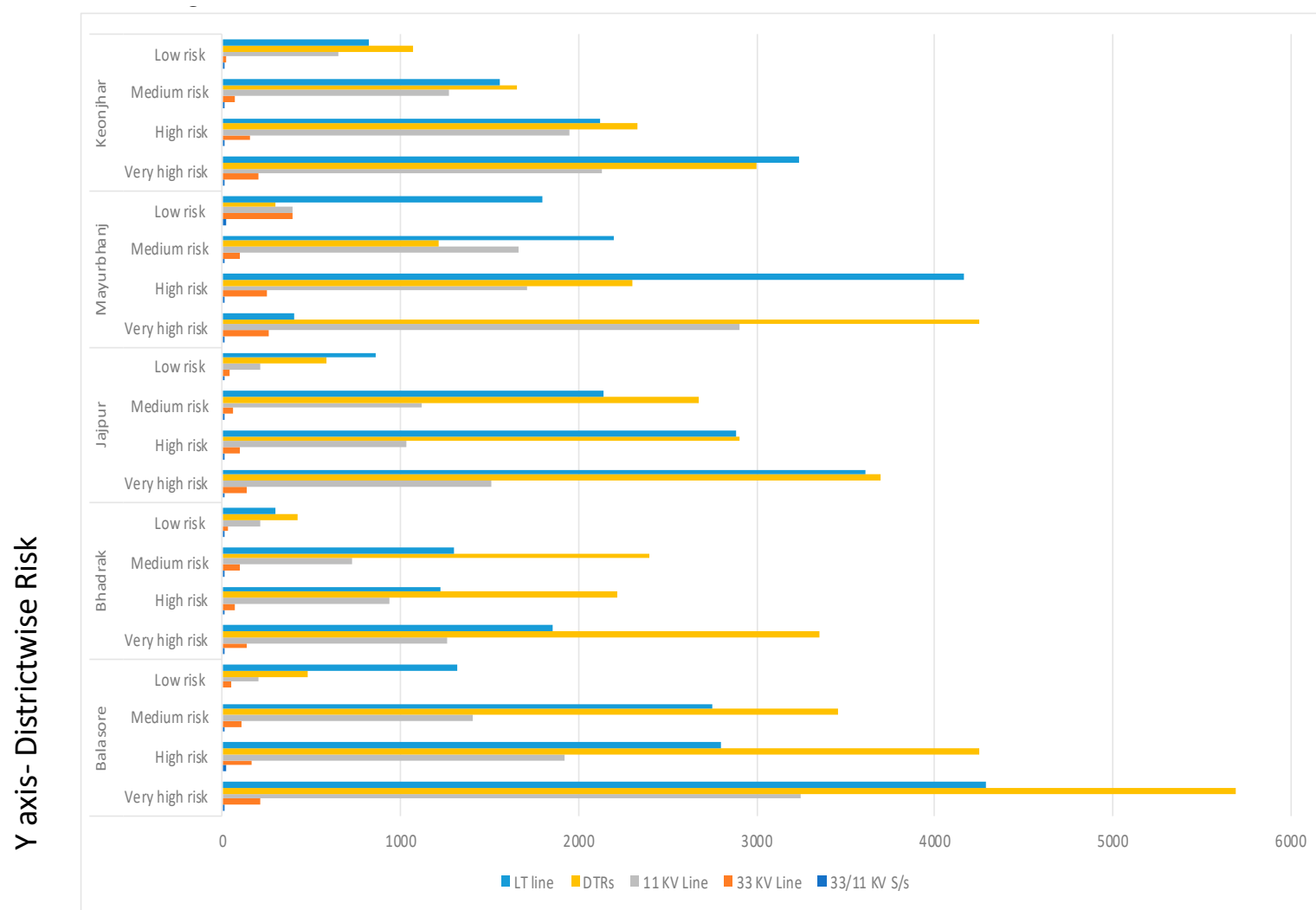

$X$ axis- Number of units

Figure 3. Cyclone risk map of power lines in five districts of Odisha, Source: [42].

Figure 3 points out differential risk in different districts. For some districts, such as Balasore, Bhadrak and Mayurbhanj, the high risk lies with DTRs (distribution transformers), followed by LT (low tension, meaning low voltage local lines). Usually the high voltage lines have more investments and less risks; however, the key problem lies with the local lines and their distribution system. Odisha has put in place an Emergency Restoration System (ERS) with forty-two $220 \mathrm{kV}$ towers and two $400 \mathrm{kV}$ towers. Further, after cyclone Phailin, the Disaster Response Centers (DRCs) proposed the establishment of Chandaka and Meramundali with state-of-the-art Safety and IT and Communication infrastructures. 


\subsection{Case Studies of Cyclones}

The super cyclone of 29th October 1999 was one of the most severe of all cyclones with a 50-year return to impact India [41]. The cyclone led to the damage of telecommunication lines, water supplies, roads, irrigation and power supplies. As many as 36 towers along $220 \mathrm{kV}$ and $130 \mathrm{kV}$ lines suffered irreparable damage or total collapse in the coastal districts, Bhubaneswar and Cuttack [42]. The power disruptions in Bhubaneswar and Cuttack city lasted for four days while the power in the other districts was restored by 15th December 1999. Human resource support was provided by GRIDCO and was also pulled in from the adjoining state of Andhra Pradesh. Of INR 6227.59 crores ( 1 crore is 10 million) requested from the government of India, only 400 crores were earmarked for the energy department.

2013 Cyclone Phailin: A very severe cyclone named Phailin made landfall on the 12th October 2013, followed by flooding in Odisha. In total, 18 out of 30 districts in the state were affected [43]. The majority of the damages were due to high winds speeds of up to $220 \mathrm{kmph}$, followed by flooding due to heavy rainfall. The cyclone resulted in the deaths of 44 people and affected about 13.2 million people in over 18,370 villages. It caused extensive damages, particularly to houses, standing crops, and power and communication infrastructure. The power infrastructure was severely affected among all the other public infrastructures. A total of 1756 feeders, 38,997 substations, 36,133.9 km of LT (low tension) line, $4074 \mathrm{~km}$ of EHT (extra high tension) line and 211,014 electric poles had been damaged due to the combined effects of the cyclone and floods. Furthermore, seventy-one $220 \mathrm{kV}$ and twenty-one $132 \mathrm{kV}$ towers were damaged [42]. A total of 38.09 lakh (1 lakh is 100,000) consumers were affected and the power supply was restored to 27 lakh households by December 2013. As a preparedness measure, the Energy Department mobilized manpower and materials to the districts likely to be affected to ensure the prompt restoration of power supply. All the government departments were asked to make arrangements for their own power backup. A sum of INR 1048.14 crore was requested for the restoration of the power supply out of INR 4242.41 .297 crore that was asked for.

2014 Cyclone Hud Hud [44]: Cyclone Hud Hud made landfall on 12th October 2014 at Vishakapatnam. It impacted as many as 15 districts of the State of Odisha. The restoration of roads and electricity and water supply was performed within 12-48 h. The power sector, as in 2013 with cyclone Phailin, was the worst affected due to high wind speed. The distribution infrastructure, particularly $11 \mathrm{kV}, 33 \mathrm{kV}$ and LT lines and Distribution Transformers suffered heavy damage due to cyclone Hud Hud and subsequent rainfall. A massive 700,000 consumers were affected and $239.95 \mathrm{~km}$ of $33 \mathrm{kV}$ lines, $2155.99 \mathrm{~km}$ of $11 \mathrm{kV}$ lines, $1088.75 \mathrm{~km}$ of LT lines, 1754 distribution transformers and 8 power transformers were damaged. Human resources and materials were mobilized by the DISCOMs and District Administration for the restoration of the power supply. INR 5 crore was provided for the immediate restoration of the power supply. INR 60 crore was spent by the State for the restoration of the electricity which was not covered under the National Disaster Response Fund (NDRF) and State Disaster Response Fund (SDRF).

Cyclone Fani, 2019: The very recent Cyclone Fani of 2019 resulted in serious damage and the disruption of critical services and infrastructures in 14 districts of Odisha [45]. The wind speed was reported to be more than $230 \mathrm{~km}$ per hour along with heavy rainfall for four hours. Cyclone Fani caused a major setback to the state, with total losses to the tune of INR 24,176 crore. Damage to the power sector remains very high. The power infrastructure in the 14 affected districts consists of about 500 substations and 110,000 distribution transformers. These are connected with a total of approximately 14,000 transmission lines and $190,000 \mathrm{~km}$ of distribution lines. While damage to the transmission system was minor, damage to the distribution system included approximately $80,600 \mathrm{~km}$ of distribution lines, 202 distribution substations, and 13,400 transformers. The total damage was assessed at INR 8139 crore and corresponds to the requirement of "bringing back the system to the pre-cyclone level". Another INR 253.5 crore was lost in revenue, bringing the total loss of the power sector to INR 8392.50 crore.

Figure 4 summarizes the cyclone risk and damages over last 20 years. Figure 4 shows the cyclone hazard map of Odisha. Figure 5 shows the affected districts in four major cyclones in last 20 years 
in Odisha. There is a very strong correlation between the two figures, which suggests that the most affected areas for cyclones in the state are in the south-eastern and north-eastern costal districts. Table 1 shows the details of the damages.

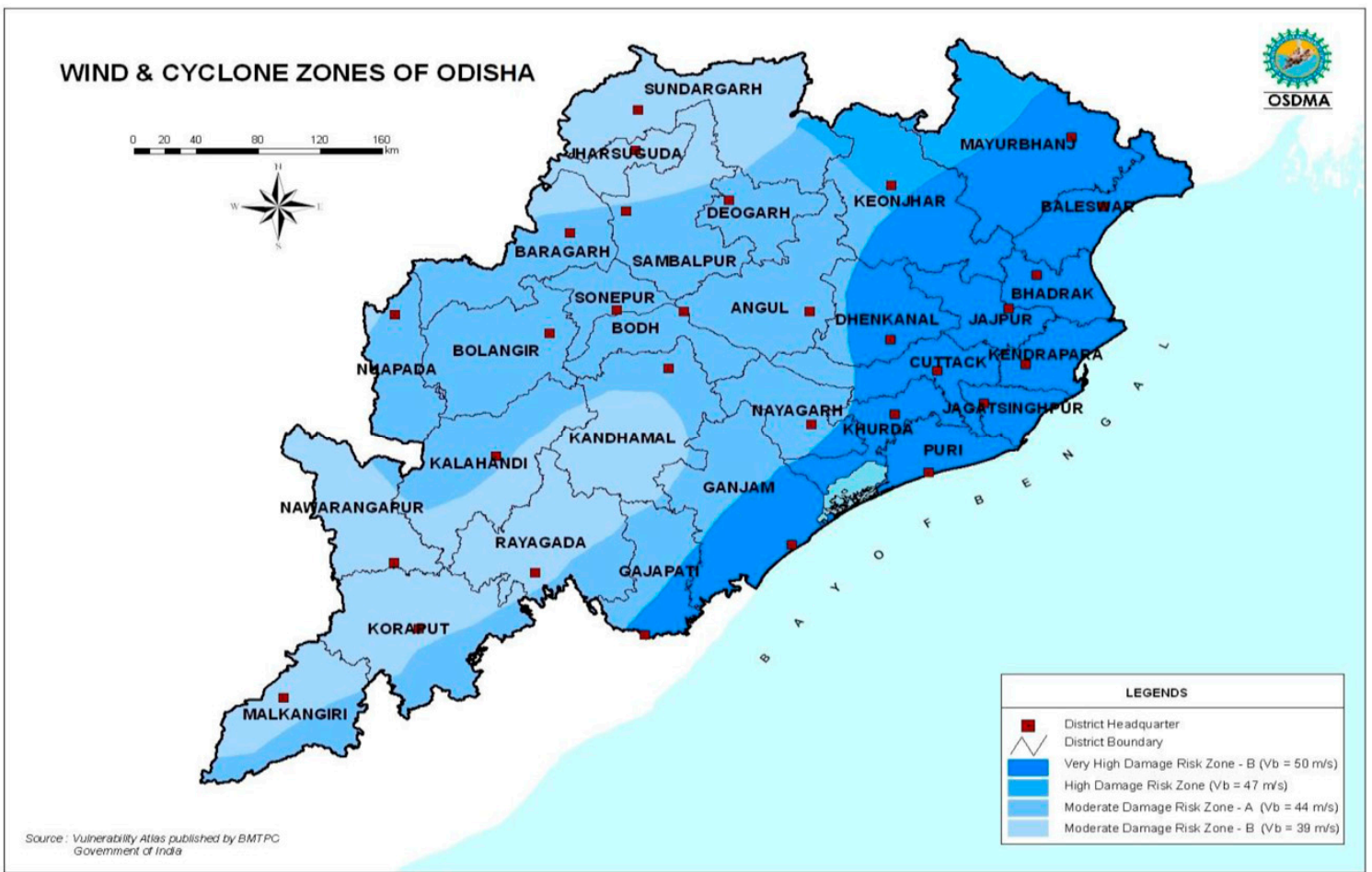

Figure 4. Cyclone risk in Odisha [46].

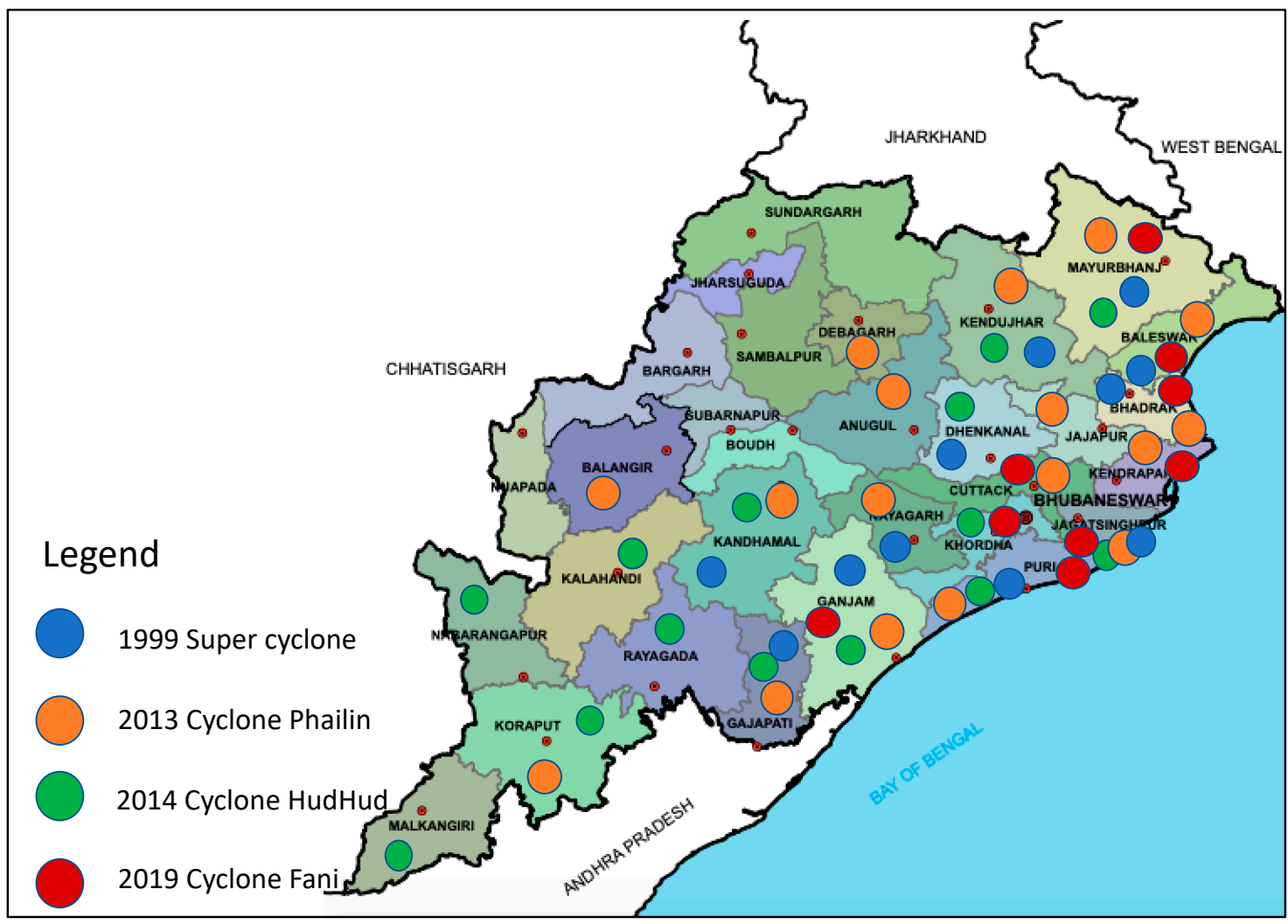

Figure 5. Cyclone affected districts of Odisha. Source: Author. 
Table 1. Total Damage and Damage to Power Sector by Cyclones (in INR crores).

\begin{tabular}{ccccccc}
\hline Year & $\begin{array}{c}\text { Name of the } \\
\text { Cyclone }\end{array}$ & $\begin{array}{c}\text { Districts } \\
\text { Affected }\end{array}$ & $\begin{array}{c}\text { Peak Wind } \\
\text { Speed } \mathbf{( k m} / \mathbf{h})\end{array}$ & $\begin{array}{c}\text { Total } \\
\text { Damage }\end{array}$ & $\begin{array}{c}\text { Damage to } \\
\text { Electricity }\end{array}$ & $\begin{array}{c}\text { \% of Total } \\
\text { Damage }\end{array}$ \\
\hline 1999 & Super cyclone & 14 & $260-270$ & 6227.59 & 400.00 & 6.42 \\
\hline 2013 & Phailin & 19 & 214 & 4242.41 & 1048.14 & 24.70 \\
\hline 2014 & Hudhud & 11 & $80-100$ & 779.00 & 60.00 & 7.70 \\
\hline 2018 & Titli & 17 & $130-140$ & 2779.32 & 133.03 & 4.78 \\
\hline 2019 & Fani & 9 & 205 & $24,176.00$ & 8139.00 & 33.66 \\
\hline 2019 & Bulbul & 9 & 110 & 224.42 & 6.26 & 2.7 \\
\hline \multicolumn{7}{r}{} \\
\end{tabular}

\subsection{Funds for Building Resilience in Power Sector in Odisha}

According to the Damage, Loss and Needs Assessment (DLNA) report for Cyclone Fani in Odisha, for power systems to be resilient and withstand high wind speeds and heavy rains, three approaches for recovery could be adopted, as shown in Figure 5:

1. An immediate approach to use the existing design systems with proper foundations and reduced spans. This may be cost efficient but may not be long-lasting.

2. To use a combination of spun concrete poles and H-poles, which can withstand wind speeds of up to $250 \mathrm{~km}$ per hour (kmph).

3. The ideal method for building long term resiliency in the power sector would be to shift from overhead lines to underground cables.

Figure 6 shows tentative cost of strengthening resilience in the power sector.

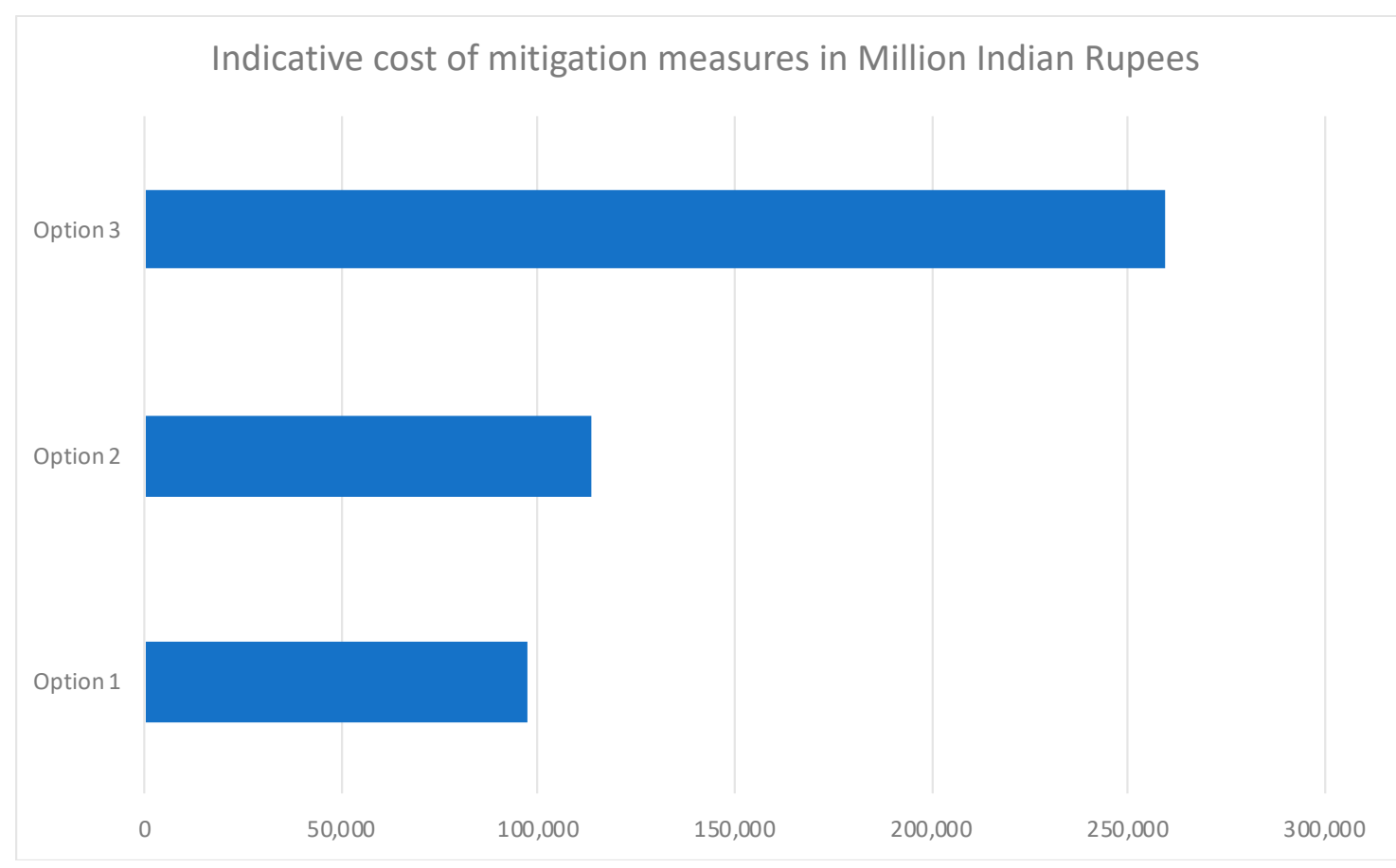

Figure 6. Tentative cost of strengthening resilience in the power sector (USD 1 USD $=$ INR 75) Source: Author.

Until now, in the power sector, two externally funded projects have been taken up for the Odisha state. In 1996, multilateral funding was approved for the Orissa Power Sector Restructuring Project. 
The World Bank, the International Bank for Reconstruction and Development (IRDB), the Asian Development Bank and the British Department for International Development (DFID) supported the project. One of the objectives of the project was to upgrade the power sector's environmental performance and strengthen the environmental management capabilities of the new utilities [46-49]. The overall project outcome was unsatisfactory and the risk to development was reported. The other project is on environmental assessment, funded by the ADB (Asian Development Bank) in 2014.

\section{Discussion}

Cyclones are frequent hazard events in Odisha, exposing the coastal zone and also the inland at times, putting lives, livelihoods and properties at risk. In the last two decades, life loss has been efficiently brought down by the government through proper planning and co-ordinated evacuation. Having said that, the economic loss has been mounting with every disaster event in Odisha. This raises a question similar to the one raised by on locational suitability [10], addressal of the vulnerability component and the lack of redundancy of the critical infrastructure and other economic infrastructures, so as to have uninterrupted services. Interestingly, in Odisha the density of the electricity network is higher in the coastal belt and in industrial areas [42]. As a result, the chance of disruption is higher in the coastal zone. Comparing Figure 2 with Figure 4, it is evident that the $33 \mathrm{kV}, 220 \mathrm{kV}$, and some parts of $400 \mathrm{kV}$ lines and substations are at higher risk. However, the risk assessment in Figure 3 shows a high risk for low tension (voltage) lines and DTRs (distribution transformers) in some districts. While there can be arguments against the locational suitability of the industrial zones along the high-risk coastal area of Odisha, the placement of electricity networks could be more or less inevitable. Hence it is important to build resiliency into the system itself to avoid or minimize the chances of failure.

After the devastating 1971 cyclone and flood in Odisha, Mr. H.A. Ferguson, a Dutch expert, advised the state government of Odisha to prepare a comprehensive master plan to control cyclone and flood risks. Even after five decades, the master plan is yet to be formulated. This has a serious implication for land use and landcover planning by the state. In addition, the Ministry of Irrigation and Power, vide their Memorandum No. F. C. 6 (12)/71, dated the 15th November, 1971, in which a committee, headed by Dr. P. K. Kotesvvaram, examined various measures to mitigate human suffering and to reduce the loss of life and property [50]. The committee made the recommendation to include the damage of public utilities, which would include the critical infrastructure into to the state budgetary provisions. The energy department has done the risk mapping of the various installations in the five districts, as seen in Figure 3, along the coastal zone, and have put in place standard operating procedures for minimizing the disruption. The various preparedness measures taken up during cyclone Phailin have been listed by Mukhopadhyay et al. (2014). Referring to Table 1, the cost of damage is still very high and is concerning. Interestingly, the bailout schemes for the power sector in Odisha, discussed in Section 4.1, mostly follow a big disaster event in Odisha. The 2001 bailout followed the 1999 super cyclone, 2012 followed the floods and the UDAY scheme of 2015 was introduced after cyclone Phailin, which had a severe impact in terms of damage and the loss of the power sector. Similar concerns were shared by in their review of natural calamities' impact on the economy of Odisha [51].

Setting up a proper standard for $\mathrm{CI}$ is extremely important. Standards play an important role in disaster risk reduction and creating resilience. In order to be effective, they need to be rational, need to be enforced, and need to be updated regularly to keep pace with the evolving understanding of natural hazards and advancements in engineering technology. International standard setting bodies, such as the International Organization for Standardization (ISO), the International Electrotechnical Commission (IEC) and the International Telecommunication Union (ITU), develop and provide such standards for countries to voluntarily adopt. Infrastructure standards under these bodies are regularly updated and are already incorporating resilience elements towards achieving the targets of the Sendai Framework. For example, the United Nations Office for Disaster Risk Reduction (UNISDR) agreed in 2015 (within the context of the Sendai Framework) to work with ISO to develop new standards for disaster-proofing cities. ISO is currently in the process of developing new indicators for resilient cities 
under their Sustainable Development in Communities project. National frameworks for design and construction standards need to be strengthened through better regulation, state-of-the-art technology, incentives (financial and non-financial) and innovation. These frameworks should incorporate the structural engineering aspects of physical infrastructure, as well as the operation and maintenance of this infrastructure. A lack of operation and maintenance standards can increase the impact of hazard events, or even trigger new ones (e.g., urban floods due to inadequate maintenance of sewage systems) [9].

From Table 1, one can infer that the damage to the power sector is proportional to the wind speed and extent of critical assets exposed. The case of the 1999 super cyclone may stand out due to its lower damage percentage inspite of having windspeed of $260 \mathrm{~km} / \mathrm{h}$. In addition, there was funding from external agencies, as mentioned in Section 4.5, the state government cushioned 180 crores from that fund for the reconstruction in the cyclone-affected districts [52]. Robust electrical networks ensure an uninterrupted power supply and improve the government's ability to recover from disasters in a faster and stronger manner. As a result, investing in a robust electrical network is central to ensuring the social and economic health of communities within the state. Vulnerable locations need to be identified and provided with resilient infrastructure with a reliable power supply on a continuous basis. Areas to be covered by underground cables or overhead lines, or a combination of both should be identified and prioritized based on the vulnerability of the area. The standardization of the various equipment and materials and strict quality checks for the suppliers or manufacturers may be needed to build a resilient power sector in Odisha.

As mentioned above, the critical infrastructure resilience can be analyzed with the $4 \mathrm{R}$ concept (robustness, redundancy, rapidity and resourcefulness). Electrical power system robustness is defined as the intrinsic capacity of an electrical power system to maintain assigned disturbance levels when external conditions change [53]. has discussed the robustness of the power sector in terms of the northeast blackout of 2003 in the USA. It needs to analyze the important nodes for power failure. The risk assessment presented in Figure 3 has pointed out LT lines and DTRs as having very high risk. The cyclone risk map and the affected districts' maps presented in Figure 4 shows the potential high-risk districts for cyclones. Combining these two sets of data and looking at the distribution line presented in Figure 2, it is important to make comprehensive risk map for understanding the robustness of the power sector.

In electrical power systems, the term "redundancy" indicates the use of duplicate devices. However, in process control systems, "redundancy" is defined as a system that consists of several different devices with the same function and a decision system that verifies the outcome [54] made a report for the privatization of the power sector (especially the distribution system) of Odhisa and argued that it would enhance the redundancy of the electric distribution system both in normal as well as emergency times. A new regulatory system is required to privatize the power sector and develop redundancy in the system. A proper zonation of the state, based on high, medium and low cyclonic risk, and a planned distribution will be effective.

Rapidity in the $4 \mathrm{R}$ concept refers to the rapid restoration of the system after a failure. For that to happen, trained human resources, equipment and vehicles are required. Both the NDRF (National Disaster Response Force) and Odhisa Disaster Response and Rescue Force (ODRRF) are well trained for the emergency restoration of power sectors and have proven their capacities in past several disasters.

Regarding resources, the Indian power sector has been reeling under enormous financial pressure over the last few decades [55]. Distribution companies (DISCOMs), a crucial part of the power sector, have been at the center of this. One of the key concerns has long been the inability of these companies to improve their operational and financial efficiencies. A significant challenge faced by DISCOMs in India is the increasing Average Technical and Commercial losses (ATC), which are primarily caused by power theft, poor payment collection procedures, and inadequate tariff hikes. Recently, it has been awarded the Letter of Intent by the Odisha Electricity Regulatory Commission for the distribution and supply of electricity in Odisha's five circles which constitute the Central Electricity Supply of Odisha. 
The privatization of DISCOMs will assist in reducing transmission and distribution inefficiencies and improving the health of the distribution companies, which is crucial to attracting long term capital in the sector. Some of the resource-related challenges can be addressed by the SDMF (State Disaster Management Fund), which can be used to upgrade the power infrastructures to cope with increasing disaster risks.

As per the Disaster Management Act 2005, each SDMA (State Disaster Management Authority) can establish a State Disaster Mitigation Fund (SDMF), review mitigation works and approve disaster management plans of the departments. As a result, the national mitigation funds do not flow into the SDMF which would had been beneficial for carrying out mitigation work. This makes the Government of Odisha highly dependent on external funding sources for the taking up of disaster mitigation measures or the use of the state budget to fund mitigation works. This issue has its foundation in the establishment of OSDMA and a non-functional SDMA in Odisha. Furthermore, in the post disaster phase, as per the guidelines laid down by the energy department, the aim is to restore the power service with minimum disruption. This approach undermines the resilience building approach.

The risk assessment of the power sector in Odisha, taken up by the Energy department does not account for cascading disasters and hence, in such cases the drawn-up plan would not be effective. Following [29], for Odisha, risk management should be scenario-based and needs to be integrated to maximize efficiency. In the past, human resources were pulled in from neighboring states, which indicates the need for skilled manpower and training. The power sector can be considered as a grid and the impact of its disruption and consequential implications for the other critical infrastructure can be studied. The OSDMA (Odisha State Disaster Management Authority) which is in charge of training and preparedness in the state has no provisions for the training of power sector human resources. Although the current status of OSDMA is more of a knowledge management/policy support body, it can be argued that OSDMA needs certain regulatory and disaster related compliance functions. This may include providing DRR (disaster risk reduction) compliance for any major infrastructure projects, setting up minimum standards for coastal/inland infrastructures, etc. OSDMA can utilize SDMF, mentioned above for the resilience building of the power sector as a critical infrastructure, especially to upgrade the coastal areas' power infrastructure to withstand wind speeds of $200 \mathrm{kmph}$ (category 4 and above cyclones).

Furthermore, access to information and knowledge, and the availability of capacity, are fundamental to effective climate and disaster risk reduction actions. Decision makers, investors, and practitioners in infrastructure development require access to actionable information and knowledge that enables the formulation of policies and programs or projects that are supportive of their climate and development objectives. In addition, given the complex uncertainties associated with climate change and its impact, and thus the complex requirements for the effective management of climate and disaster risks, all infrastructure development stakeholders need to be assisted in strengthening their capacity to plan, develop, design and implement climate-resilient policies and programs or projects. Commissioning targeted research, documenting actual project experience as part of ongoing monitoring, learning efforts, implementing knowledge and supporting technical assistance projects are some of the urgent steps required. The educational courses (degree, diploma and certificate) need to integrate the basics of disaster risk management into the course curriculum.

\section{Conclusions}

The frequency of cyclones, especially stronger ones, has been increasing on the eastern coast of India in the last five decades [56], which may be attributed to climate change. The Government of Odisha has made tremendous strides in the last two decades in protecting lives during disasters. On the other hand, the economic damage to the critical infrastructure has been mounting. The power sector is the most crucial of the critical infrastructures in the present conditions. From this study, it is evident that losses to the power sector in the last two decades have been very high, especially with cyclones with more than $200 \mathrm{~km} / \mathrm{h}$ wind speeds (cyclone of category 4 and above) [57]. 
In order to build resilience in the power sector in Odisha, the steps taken up by the government mostly correspond to the rapidity of service restoration, while the state still lacks the resources in terms of funds and manpower, creating a redundancy of alternate power source and making robust physical infrastructure which can withstand wind speeds of $200 \mathrm{~km} / \mathrm{h}$ and above. A systematic approach, especially to identify the interlinkages between different critical infrastructures and governance, will help in strengthening resiliency. The master planning of critical infrastructures based on the risk assessment and the establishment of funding mechanisms for mitigation measures are other necessary steps to be taken into consideration by the government of Odisha.

The 4R principle points out that Odhisa's power sector needs robustness through multi-hazard risk assessment, including the cascading effects of disasters. Redundancy needs to be increased through public-private cooperation. Rapid response is the strength of Odhisa, with its effective response force. Resourcefulness is a major challenge of all of the power sectors in India, however, the State Disaster Management Fund can be used to enhance/upgrade their facilities to cope with increasing climate and disaster risk.

Specific standards need be created, and there should be a specialized agency, such as OSDMA to monitor the implementation of those standards for critical infrastructures, such as the power sector. This must be well coordinated between the power sector and the disaster management sector with proper legislative measures. Training, capacities and knowledge management need to be enhanced with the cooperation of local technical institutions.

One of the limitations of the paper lies in the fact that it provides qualitative analysis and draws policy recommendations but does not make detailed analysis of the quantitate cost benefit analysis of resilient infrastructures. Future research needs to explore the cost benefit analysis of critical infrastructure, which can be linked to specific policy analysis.

Funding: This research received no external funding.

Acknowledgments: Authors acknowledge the support from India Japan Center of Keio University.

Conflicts of Interest: The authors declare no conflict of interest.

\section{References}

1. UNDRR. Words into Action Guidelines: Cross-Sectoral and Multi-Risk Approach to Cascading Disasters. 2017. Available online: https://www.preventionweb.net/files/52828_ccrosssectoralmultirisk\%5b1\%5d.pdf (accessed on 2 June 2020).

2. UNDRR. Sendai Framework for Disaster Risk Reduction; United Nations: New York, NY, USA, 2015.

3. ADB. Meeting Asia's Infrastructure Needs; Asian Development Bank: Manila, Philippines, 2017.

4. Lu, X. Building Resilient Infrastructure for the Future: Background Paper for G20 Climate Sustainability Working Group; Asian Development Bank: Manila, Philippines, 2019; 38p.

5. ADB. A Region at Risk: The Human Dimensions of Climate Change in Asia and the Pacific; Asian Development Bank: Manila, Philippines, 2017.

6. Studer, J.A. Earthquake. 2007. Available online: http://cidbimena.desastres.hn/docum/crid/Septiembre2007/ CD1/pdf/eng/doc12107/doc12107-7.pdf (accessed on 2 June 2020).

7. Ministry of Power. Crisis and Disaster Management Plan for Power Sector; Ministry of Power: New Delhi, India, 2017.

8. Koyama, K. Background and Impacts of World's Largest Blackout in India; IEEJ August 2020. 2012. Available online: https://eneken.ieej.or.jp/data/4518.pdf (accessed on 2 June 2020).

9. IWRI. International Workshop on Disaster Resilience Infrastructure; IWRI: New Delhi, India, 2018.

10. Pescaroli, G.; Alexander, D. Critical Infrastructure Panarchies and the Vulnerability Paths of Cascading Disasters. Nat. Hazards. 2016, 82, 175-192. [CrossRef]

11. OECD. Good Governance for Critical Infrastructure Resilience, OECD Reviews of Risk Management Policies; OECD Publishing: Paris, France, 2019. [CrossRef] 
12. The European Parliament and the Council of the European Union. Council Directive 2008/114/EC of 8 December 2008 on the identification and designation of European critical infrastructures and the assessment of the need to improve their protection. Off. J. Eur. Union. 2008, 16, 75-82.

13. Rehak, D.; Senovsky, P.; Slivkova, S. Resilience of Critical Infrastructure Elements and Its Main Factors. Systems 2018, 6, 21. [CrossRef]

14. Holling, C.S. Resilience and Stability of Ecological Systems. Ann. Rev. Ecol. Syst. 1973, 4, 1-23. [CrossRef]

15. Olshansky, R.B.; Kartez, J.D. Managing land use to build resilience. In Cooperating with Nature: Confronting Natural Hazards with Land-use Planning for Sustainable Communities; Burby, R., Ed.; Joseph Henry Press: Washington, DC, USA, 1998; pp. 167-201.

16. Luthar, S.S.; Cicchetti, D.; Becker, B. The construct of resilience: A critical evaluation and guidelines for future work. Child Dev. 2000, 71, 543. [CrossRef] [PubMed]

17. Bruneau, M.; Reinhorn, A. Overview of the Resilience Concept. In Proceedings of the 8th U.S. National Conference on Earthquake Engineering, San Francisco, CA, USA, 2006.

18. Rose, A. Economic Resilience to Disastersin Paton, D. and Johnston, D. Disaster Resilience: An Integrated Approach; Charles C Thomas: Springfield, Il, USA, 2006; pp. 226-248.

19. Hill, R.; Paton, D. Managing Company Risk and Resilience through Business Continuity Management; Charles S. Thomas Publishers: Springfield, IL, USA, 2006.

20. Godschalk, D.R. Urban Hazard Mitigation: Creating Resilient Cities. Nat. Hazards Rev. 2003, 4. [CrossRef]

21. Norris, F.H.; Stevens, S.P.; Pfefferbaum, B.; Wyche, K.F.; Pfefferbaum, R.L. Community Resilience as a Metaphor, Theory, Set of Capacities, and Strategy for Disaster Readiness. J. Community Psychol. 2008, 41, 127-150. [CrossRef] [PubMed]

22. Dahlberg, R.; Johannessen-Henry, C.T.; Raju, E.; Tulsiani, S. Resilience in Disaster Research: Three Versions. Civ. Eng. Environ. Syst. 2015, 32, 44-54. [CrossRef]

23. Burby, R.; Deyle, R.; Godschalk, D.; Olshansky, R. Creating hazard resilient communities through land-use planning. Nat. Hazards Rev. 2000, 1, 99-106. [CrossRef]

24. Carlson, L.; Bassett, G.; Buehring, W.; Collins, M.; Folga, S.; Haffenden, B.; Petit, F.; Phillips, J.; Verner, D.; Whitfield, R. Resilience Theory and Applications; ANL/DIS-12-1; Argonne National Laboratory, Decision and Information Sciences Division: Argonne, IL, USA, 2012.

25. Petit, F.; Bassett, G.; Black, R.; Buehring, W.; Collins, M.; Dickinson, D.; Fisher, R.; Haffenden, R.; Huttenga, A.; Klett, M.; et al. Resilience Measurement Index: An Indicator of Critical Infrastructure Resilience; Argonne National Laboratory: Chicago, IL, USA, 2013.

26. Rinaldi, S.M.; Peerenboom, J.P.; Kelly, T.K. Identifying understanding and analyzing critical infrastructure interdependencies. IEEE Control Syst. Mag. 2001, 21, 11-25.

27. DeBruijne, M.; Eeten, M.V. Systems that Should Have Failed: Critical Infrastructure Protection in an Institutionally Fragmented Environment. J. Conting. Crisis Manag. 2007, 42, 45-51.

28. Ehlan, M.A.; Vargas, V.N. Multi-hazard, multi-infrastructure, economic scenario analysis. Environ. Syst. Decis. 2013, 33, 60-75. [CrossRef]

29. Karagiannis, G.M.; Chondrogiannis, S.; Krausmann, E.; Turksezer, Z.I. Power Grid Recovery after Natural Hazard Impact; EUR 28844 EN; European Commission: Luxembourg, 2017. [CrossRef]

30. Rajmohan, T.; Prabhu, R.; Subbarao, G.; Palanikumar, K. Optimization of machining parameters in electrical discharge machining (EDM) of 304 stainless steel. Procedia Eng. 2012, 38, 1030-1036. [CrossRef]

31. Wataya, E.; Shaw, R. Measuring the value and role of soft assets in smart city development. Cities 2019, 94, 106-115. [CrossRef]

32. ADB. STRATEGY 2030: Achieving a Prosperous, Inclusive, Resilient, and Sustainable Asia and the Pacific; ADB: Manila, Philippines, 2018.

33. Renda, A.; Hammerli, B. Protecting Critical Infrastructure in the EU CEPS Task Force Report, SSRN. 2010. Available online: https://ssrn.com/abstract=1756710 (accessed on 2 June 2020). [CrossRef]

34. Theocharidou, M.; Giannopoulos, G. Risk assessment methodologies for critical infrastructure protection. Part II: A new approach. JRC Sci. Policy Rep. 2015, 23, 34-36.

35. Brown, R.; Prudent-Richard, G.; O’Mara, K. Enhancing Power Sector Resilience: Emerging Practices to Manage Weather and Geological Risks; World Bank: Washington, DC, USA, 2016.

36. Government of Odisha. Memo. Very Sev. Cyclonic Storm. 2014. Available online: http://www.odisha.gov.in/ disaster/src/Cyclone_Hud-Hud/memorandum_Hudhud.pdf (accessed on 1 April 2020). 
37. Kalsi, S.R. Orissa super cyclone-A synopsis. Mausam 2006, 57, 1.

38. GIHUB. Global Infrastructure Outlook. 2018. Available online: https://outlook.gihub.org (accessed on 21 May 2020).

39. Odisha Disaster Management Policy; Government of Odisha: Odisha, India, 2005.

40. Odisha Disaster Management Plan; Government of Odisha: Odisha, India, 2019.

41. Chittibabu, P.; Dube, S.K.; Macnabb, J.B.; Murty, T.S.; Rao, A.D.; Mohanty, U.C.; Sinha, P.C. Mitigation of Flooding and Cyclone Hazard in Orissa, India. Nat. Hazards 2004, 31, 455-485. [CrossRef]

42. Odisha Disaster Management Plan; Government of Odisha: Odisha, India, 2015.

43. Memorandum "PHAILIN" 2013. Government of Odisha. Available online: https://srcodisha.nic.in/calamity/ MEMORANDUM.pdf (accessed on 2 June 2020).

44. Memorandum "HUD HUD" 2014. Government of Odisha. Available online: https://srcodisha.nic.in/ calamity/Memorandum\%20Cyclone\%20Hudhud\%202014.pdf (accessed on 2 June 2020).

45. Memorandum FANI 2019. Government of Odisha. Available online: https://srcodisha.nic.in/calamity/ Memorandum_Cyclone\%20FANI_3rd\%20May\%202019.pdf (accessed on 2 June 2020).

46. OSDMA. Annual Report; Government of Odisha: Odisha, India, 2019.

47. Memorandum TITLI 2018. Government of Odisha. Available online: https://srcodisha.nic.in/calamity/Final\% 20Memorandum\%20-\%20TITLI.pdf (accessed on 2 June 2020).

48. Memorandum Bulbul 2018. Government of Odisha. Available online: https://srcodisha.nic.in/calamity/ emorandum\%20OF\%20Bulbul.pdf (accessed on 2 June 2020).

49. World Bank. 2020. Available online: https://projects.worldbank.org/en/projects-operations/project-detail/ P035170\#finances (accessed on 2 June 2020).

50. Odisha Relief Code; Government of Odisha: Odisha, India, 2018.

51. Sarangi, P.; Penthoi, G.C. Economic Implications of Natural Disasters in Orissa: A Retrospective View, Orissa Review; Information \& Public Relations Department, Government of Odisha, Printed at Odisha Government Press: Madhupatna, Cuttack, India, 2005.

52. GRIDCO Website. 2020. Available online: http://www.diorissa.nic.in/gridco.htm (accessed on 2 June 2020).

53. Zhang, W.; Pei, W.; Guo, T. An efficient method of robustness analysis for power grid under cascading failure. Saf. Sci. 2014, 64, 121-126. [CrossRef]

54. TERI. Privatization of Electricity Distribution in Odisha: A Case Study; TERI Report: New Delhi, India, 2002; 284p.

55. MERCOM. Privatizing DISCOMs the Way out of Their Financial Mess, Written by Shaurya Bajaj. Available online: https://mercomindia.com/privatizing-discoms-financial-mess/ (accessed on 21 May 2020).

56. Basheer Ahammed, K.K.; Pandey, A.C. Coastal Social Vulnerability and Risk Analysis for Cyclone Hazard Along the Andhra Pradesh, East Coast of India. KN J. Cartogr. Geogr. Inf. 2019, 69, 285-303. [CrossRef]

57. Crisil Report. Diagnostic study of the power distribution sector, Crisil for Niti Aayog, April 2019. Available online: https://niti.gov.in/sites/default/files/2019-08/Final\%20Report\%20of\%20the\%20Research\% 20Study\%20on\%20Diagnostic\%20Study\%20for\%20power\%20Distribution_CRISIL_Mumbai.pdf (accessed on 2 April 2020).

(C) 2020 by the authors. Licensee MDPI, Basel, Switzerland. This article is an open access article distributed under the terms and conditions of the Creative Commons Attribution (CC BY) license (http://creativecommons.org/licenses/by/4.0/). 